
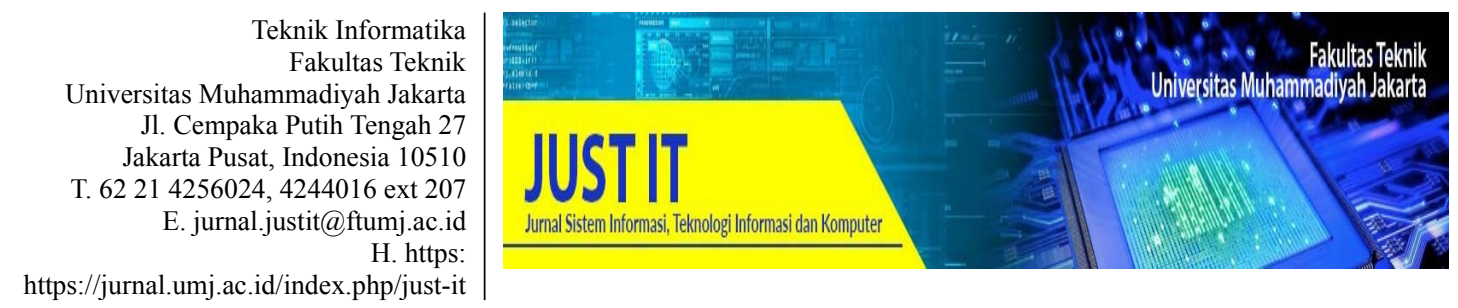

\title{
SISTEM PENENTUAN PENERIMA SHODAQO MENGGUNAKAN METODE SIMPLE ADDITIVE WEIGHTING
}

\author{
Anjar Hero Wilarto ${ }^{1}$, Umniy Salamah ${ }^{2}$ \\ ${ }^{1}$ Teknik Informatika, Fakultas Ilmu Komputer, Universitas Mercu Buana \\ umniy.salamah@mercubuana.ac.id ${ }^{2}$
}

\begin{abstract}
Abstrak
Pada umumnya pemberian shodaqa dapat dilakukan di Musholla, dan pada Musholla At-Taqwa proses pemberian shodaqo masih dilakukan dengan cara pendataan data diri dan penentuan penerima Shodaqo. Dalam melakukan pendataan, panitia dari shodaqo harus melakukan survey, atau calon penerima bisa mengisi data diri ke musholla. Aktivitas tersebut sangat menyita waktu dan tidak efektif, sehingga diperlukan sistem yang lebih efektif sebagai media dalam menentukan seseorang yang layak mendapatkan shodaqo serta menguji metode SAW (Simple Additive Weighting) untuk memberikan rekomendasi peserta yang layak mendapatkan shodaqo. Ada beberapa kriteria yang diberikan oleh panitia untuk penerima shodaqo seperti data tempat usaha, data rumah, data pekerjaan, data inventaris, dan data penghasilan. Selanjutnya kriteria diolah menggunakan aplikasi yang dibangun menggunakan menggunakan metode Simple Additive Weighting. Hasil dari perangkingan diatas diperoleh V1 $=0.666$ dan V2 $=1$. Dan dengan data hasil perangkingan diatas dapat disimpulkan bahwa V2 yang berhak dalam menerima shodaqa karena telah sesuai dengan kriteria yang ditentukan. Sistem ini terbukti dapat membantu proses penentuan penerima shodaqa berdasarkan data kriteria yang telah dipilih oleh user dan memudahkan pihak panitia. Sistem ini diharapkan dapat menjadi alat bantu untuk proses pengambilan keputusan dalam penentuan penerima shodaqo di Musholla At- Taqwa.
\end{abstract}

Kata Kunci: Shodaqo, Simple Additive Weighting, Sistem Pendukung Keputusan, Pembuatan Keputusan, Musholla.

\begin{abstract}
In general, giving shodaqa can be done in Musholla, and at At-Taqwa Musholla the process of giving shodaqo is still done by collecting data and determining Shodaqo recipients. In conducting data collection, the committee of shodaqo must conduct a survey, or prospective recipients can fill out their personal data to the mosque. These activities are very timeconsuming and ineffective, so we need a more effective system as a medium in determining someone who deserves shodaqo and testing the SAW (Simple Additive Weighting) method to provide recommendations for participants who deserve to get shodaqo. There are several criteria given by the committee for shodaqo recipients such as business location data, home data, employment data, inventory data, and income data. Furthermore, the criteria are processed using applications that were built using the Simple Additive Weighting method. The results of the above ranking are obtained $\mathrm{V} 1=0.666$ and $\mathrm{V} 2=1$. And with the ranking data above it can be concluded that V2 is entitled to receive shodaqa because it is in accordance with specified criteria. This system is proven to help the process of determining shodaqa recipients based on criteria data chosen by the user and making it easier for the committee. This system is expected to be a tool for the decision making process in determining shodaqo recipients in the At-Taqwa Mosque.
\end{abstract}

Keywords: Shodaqa, Simple Additive Weighting, Decision Support System, Decision Making, Musholla. 


\section{Pendahuluan}

Kebutuhan dasar sebagai manusia harus dibantu oleh orang lain jika individu yang bersangkutan tidak memiliki kemampuan untuk memenuhinya sendiri, dimana hal ini sejalan dengan ajaran solidaritas (Utami, Kresnawati, Saud, \& Rezki, 2017).

Saat ini, penentuan penerima shodaqo yang dilakukan masih menggunakan kertas, dimana dokumen-dokumen kertas tersebut masih memenuhi laci-laci penyimpan dokumen. Proses pencarian dokumen dari tempat penyimpanan ini dapat menjadi aktivitas yang begitu melelahkan. Dokumen yang dicari bisa saja tidak ditemukan dalam laci tersebut sehingga akan menjadi suatu aktivitas yang sangat sia-sia.

Pada saat ini perkembangan teknologi informasi semakin berkembang pesat (Agustian \& Jumaryadi, 2019). Perkembangan teknologi informasi dapat meningkatkan kinerja dan memungkinkan suatu kegiatan dilakukan dengan cepat, tepat, dan akurat, sehingga akan meningkatkan sebuah produktivitas bagi para pelakunya (Indrayani, 2012). Perkembangan teknologi informasi juga dapat dirasakan dalam beberapa aspek seperti memprediksi arus lalu lintas (Priambodo \& Jumaryadi, 2018).

Dalam melakukan pengumpulan data penerima shodaqa diharuskan mendaftar dahulu dengan mengisi data pada form yang telah disediakan. Selanjutnya dari panitia melakukan survey, untuk melakukan pendataan jika terdapat data yang masih belum lengkap, dalam pendataan ini panitia membawa catatan yang sering mengakibatkan terjadinya hilang dokumen. Dalam pengambilan keputusan pihak dari panitia masih menggunakan teknik skoring berdasarkan data yang telah dikumpulkan, dalam penggunaan teknik skoring ini akan menghasilkan nilai tidak efektif. Proses pengumpulan data seperti ini ini sangat menyita waktu (Nashar, Sukamto, \& Parashakti, 2016).

Untuk memecahkan permasalahan tersebut perlu dibuat suatu sistem pendukung keputusan yang dapat membantu panitia dalam pengambilan keputusan untuk penentuan penerima shodaqa (Kurnianda, 2019).

Metode yang digunakan dalam sistem pendukung keputusan ini adalah Metode Simple Additive Weighting (SAW), yang dilakukan dengan menentukan nilai bobot untuk setiap atribut, kemudian dilanjutkan dengan proses perangkingan yang akan menyeleksi alternatif terbaik (Mujiastuti, Komariyah, \& Hasbi, 2019). Dalam penelitian ini alternatif yang dimaksud adalah orang yang berhak menerima shodaqa berdasarkan kriteria-kriteria yang telah ditentukan. Dengan proses perangkingan tersebut, diharapkan penilaian akan lebih tepat karena didasarkan pada nilai kriteria dan bobot yang sudah ditentukan sehingga akan mendapatkan hasil yang lebih akurat terhadap siapa yang akan menerima shodaqa di wilayah tersebut (Nashar et al., 2016).

\section{Metode}

Metodologi yang digunakan dalam mengembangkan sistem pendukung keputusan penerima shodaqo ini adalah waterfall, dimana metode waterfall terdiri dari beberapa langkah sebagai berikut:

1. Komunikasi

Pada tahap awal, komunikasi dilakukan dengan melakukan wawancara terhadap DKM Mushola At Taqwa.

2. Perencanaan

Pada tahap berikutnya, jadwal rencana kerja dibuat terkait dengan sistem pendukung keputusan penerima shodaqo.

3. Pemodelan

Setelah memiliki rencana mengenai fungsi sistem yang akan dibuat, langkah selanjutnya adalah menganalisis masalah untuk membuat sistem.

\section{Konstruksi}

Langkah ini adalah proses pengkodean menggunakan pemrograman PHP. Proses desain yang telah dibuat pada langkah sebelumnya akan diimplementasikan menggunakan Pemrograman PHP. 


\section{Hasil dan Pembahasan}

\section{A. Analisis Permasalahan}

Musholla At-Taqwa merupakan suatu tempat sholat untuk yang beragama islam. Musholla At-Taqwa setiap tahunnya mempunyai kegiatan pembagian shodaqa untuk wilayah yang berada di sekitar dari mushola tersebut. Untuk tahap proses pendataan dilakukan dengan cara manual dengan dating ke musholla untuk mengisi data atau pihak panitia yang turun langsung untuk mendata masyarakat yang berada disekitar musholla At-Taqwa.

\section{B. Analisis Sistem Berjalan}

Dalam menganalisa sistem yang ada dilakukan analisa dengan melakukan observasi dan interview dengan DKM Mushola At-Taqwa dan Ketua RT setempat.

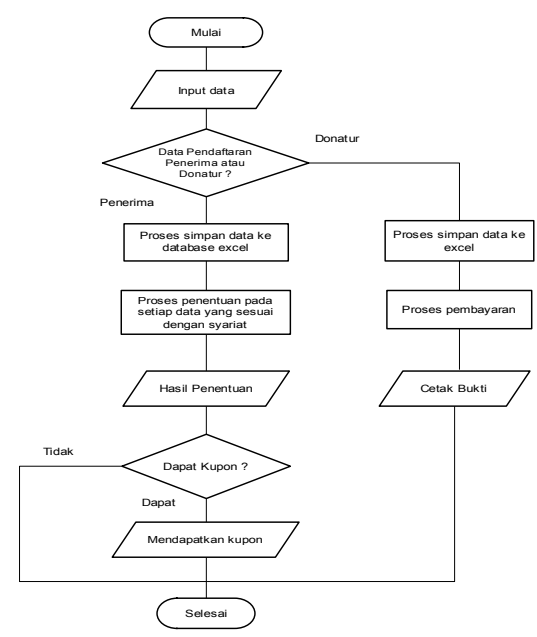

Gambar. 1. Proses Bisnis Berjalan.

Pada flowchart diatas, adalah keseluruhan sistem dimana dari alur input data, apakah data pendaftaran yang diinput itu adalah data penerima atau donator. Jika data calon penerima shodaqo maka data akan langsung di input ke excel, dan akan diproses untuk menentukan data yang berhak menerima shodaqo. Jika data yang diinput sesuai dengan syarat yang ada untuk menerima shodaqo, maka penerima akan mendapatkan kupon untuk mengambil shodaqo. Jika donatur maka akan melakukan proses pembayaran lalu cetak bukti berupa kwitansi.

\section{Perancangan Sistem}

Berikut merupakan hasil analisis dan perancangan terhadap penelitian yang dilakukan.

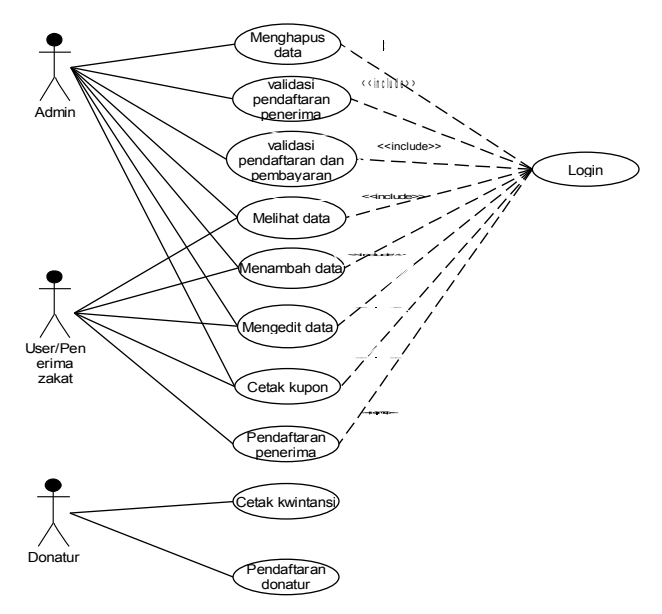

Gambar. 2. Use Case Diagram.

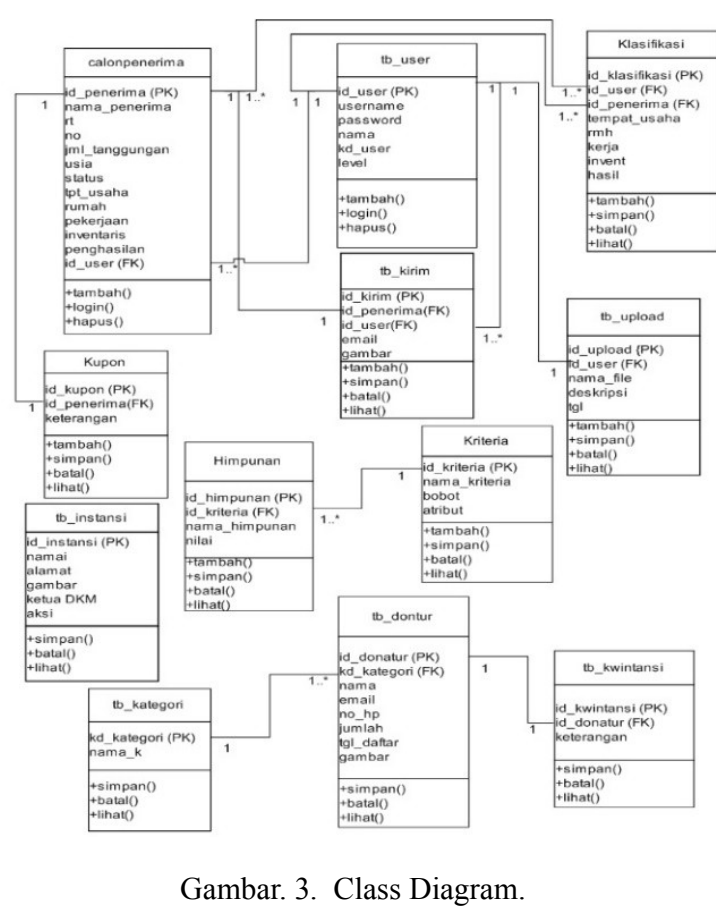

Metode Simple Additive Weighting (SAW)

Metode Simple Additive Weighting sering dikenal dengan istilah metode penjumlahan terbobot. Konsep dasar SAW adalah mencari penjumlahan terbobot dari kinerja setiap 
alternatif pada semua atribut (Mujiastuti et al., 2019).

TABEL 1

KRITERIA DAN BOBOT

\begin{tabular}{|c|l|c|}
\hline No & Nama kriteria & Bobot $(\mathrm{W})$ \\
\hline 1 & Tempat_Usaha & 0.05 \\
\hline 2 & Rumah & 0.1 \\
\hline 3 & Pekerjaan & 0.2 \\
\hline 4 & Inventaris yang dimiliki & 0.3 \\
\hline 5 & Penghasilan & 0.35 \\
\hline
\end{tabular}

TABEL 2

TEMPAT USAHA

\begin{tabular}{|c|c|c|}
\hline $\begin{array}{l}\mathrm{N} \\
\mathrm{o}\end{array}$ & Tempat Usaha & $\begin{array}{l}\text { Bobo } \\
t\end{array}$ \\
\hline 1 & Tidak Punya & 1 \\
\hline 2 & $\begin{array}{l}\text { Punya \& Punya } \quad \text { (Kekurangan } \\
\text { Modal) }\end{array}$ & 0.5 \\
\hline
\end{tabular}

TABEL 3

\begin{tabular}{|c|l|c|}
\hline No & Rumah & Bobot \\
\hline 1 & Tidak Ada & 0.25 \\
\hline 2 & Dengan rumah anak & 0.5 \\
\hline 3 & Kontrak & 0.75 \\
\hline 4 & Pribadi & 1 \\
\hline
\end{tabular}

TABEL 4

PEKERJAAN

\begin{tabular}{|c|l|c|}
\hline No & Pekerjaan & Bobot \\
\hline 1 & Blm Kerja (Tidak Kerja) & 0.5 \\
\hline 2 & Tidak tetap & 0.75 \\
\hline 3 & Tetap & 1 \\
\hline
\end{tabular}

TABEL 5

INVENTARIS

\begin{tabular}{|c|l|c|}
\hline No & Inventaris & Bobot \\
\hline 1 & $<=3.000 .000$ & 0.5 \\
\hline 2 & $>=3.000 .000$ & 1 \\
\hline
\end{tabular}

Rumus Perhitungan normalisasi matriks

$$
r_{i j}=\left\{\begin{array}{l}
\frac{x_{i j}}{\operatorname{Max} x_{i j}} \\
\text { jika jadalah atribut keberuntungan (benefit) } \\
\frac{\text { Min } x_{i j}}{x_{i j}} \\
\text { jika j adalah atribut biaya (cost) }
\end{array}\right.
$$

Gambar. 4. Rumus Perhitungan Normalisasi Matriks.

keterangan :

rij = nilai rating kinerja ternormalisasi.

$\mathrm{xij}=$ nilai atribut yang dimiliki dari setiap kriteria
Max xij = nilai terbesar dari setiap kriteria.

Min xij = nilai terkecil dari setiap kriteria.

Benefit $=$ jika nilai terbesar adalah terbaik.

Cost $=$ jika nilai terkecil adalah terbaik .

TABEL 6

DATA Pendaftar PENERIMA SHODAQO

\begin{tabular}{|l|l|l|}
\hline Ktr & Slamet & Tejo \\
\hline Tempat_usaha & Tidak Punya & $\begin{array}{l}\text { Punya } \\
\text { (Kekurangan } \\
\text { Modal) }\end{array}$ \\
\hline Rumah & Dengan anak & Kontrak \\
\hline Pekerjaan & Tetap & $\begin{array}{l}\text { Belum Kerja } \\
\text { (Tidak Kerja) }\end{array}$ \\
\hline Inventaris & $<=3.000 .000$ & $<=3.000 .000$ \\
\hline Penghasilan & $\begin{array}{l}1.500 .000<\mathrm{x} \\
<3.800 .000\end{array}$ & $<=1.500 .000$ \\
\hline
\end{tabular}

TABEL 7

HASIL ALTERNATIF

\begin{tabular}{|c|c|c|c|c|c|}
\hline \multirow{2}{*}{$\begin{array}{l}\text { Alternati } \\
\text { f }\end{array}$} & \multicolumn{5}{|c|}{ Kriteria } \\
\cline { 2 - 6 } & $\mathrm{C} 1$ & $\mathrm{C} 2$ & $\mathrm{C} 3$ & $\mathrm{C} 4$ & $\mathrm{C} 5$ \\
\hline Slamet & 0.5 & 0.75 & 1 & 0.5 & 1 \\
\hline Tejo & 1 & 0.5 & 0.5 & 0.5 & 0.5 \\
\hline
\end{tabular}

$$
\mathrm{r}_{11}=\frac{0.5}{\max (0.5 ; 1)}=0.5
$$

01

$$
\mathrm{r}_{21}=\frac{}{\max (0.5 ; 1)}=1
$$

Normalisasi :

$$
\begin{aligned}
& \mathrm{r}_{12}=\frac{\min (0.75 ; 0.5)}{0.75}=0.66 \\
& \mathrm{r}_{22}=\frac{\min (0.75 ; 0.5)}{0.5}=1
\end{aligned}
$$

Normalisasi :

$$
\mathrm{r}_{13}=\frac{\min (1 ; 0.5)}{1}=0.5
$$

$$
\mathrm{r}_{23}=\frac{\min (1 ; 0.5)}{0.5}=1
$$

Normalisasi : 


$$
\begin{aligned}
& \mathrm{r}_{14}=\frac{\min (0.5 ; 0.5)}{0.5}=1 \\
& \mathrm{r}_{24}=\frac{\min (0.5 ; 0.5)}{0.5}=1
\end{aligned}
$$

Normalisasi :

$$
\min (1 ; 0.5)
$$

Hasil Normalisasi, dapat dibentuk ke dalam matriks, sebagai berikut :

$$
\begin{aligned}
& \text { TABEL } 8 \\
& \text { HASIL NORMALISASI } \\
& \mathrm{R}=\begin{array}{|c|c|c|c|c|}
\hline 0.5 & 0.66 & 0.5 & 1 & 0.5 \\
\hline 1 & 1 & 1 & 1 & 1 \\
\hline
\end{array} \\
& \mathrm{V}_{1}=(0.5)(0.05)+(0.66)(0.1)+(0.5)(0.2) \\
& +(1)(0.3)+(0.5)(0.35) \\
& =0.025+0.066+0.1+0.3+0.175 \\
& =0.666 \\
& \mathrm{~V}_{2}=(1)(0.05)+(1)(0.1)+(1)(0.2)+(1) \\
& (0.3)+(1)(0.35) \\
& =0.05+0.1+0.2+0.3+0.35 \\
& =1
\end{aligned}
$$

Hasil dari perangkingan diatas diperoleh $\mathrm{V}_{1}=$ 0.666 dan $V_{2}=1$. Dan dengan data hasil perangkingan diatas dapat disimpulkan bahwa $\mathrm{V}_{2}$ yang berhak dalam menerima shodaqa karena telah sesuai dengan kriteria yang ditentukan.

\section{Implementasi Program}

Setelah melakukan analisis dan perancangan selesai dilakukan maka akan dilakukan implementasi.

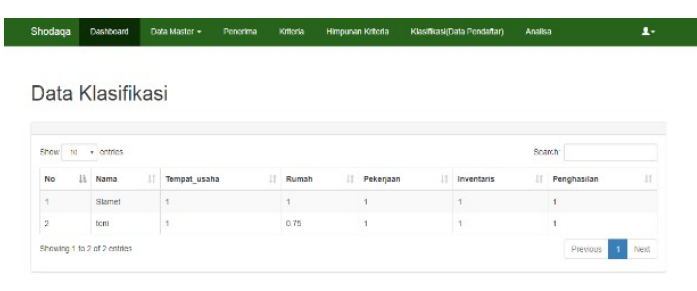

Gambar. 5. Halaman Data Klasifikasi.

Halaman ini adalah halaman klasifikasi, data penerima yang melakukan pendaftaran penerima dengan kriteria tertentu, data penerima akan terlihat disini.

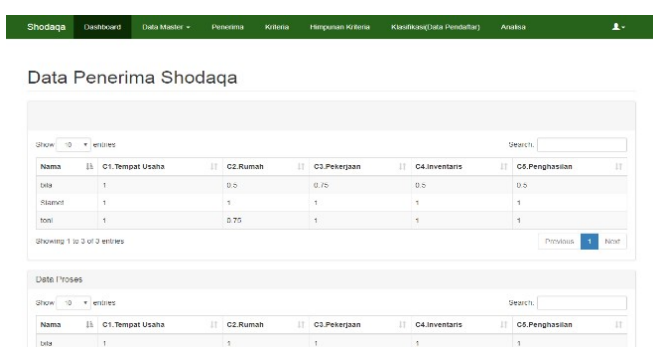

Gambar. 6. Halaman Analisa.

Halaman ini adalah halaman analisa yang akan terlihat penerima yang berhak menerima dan tidaknya.

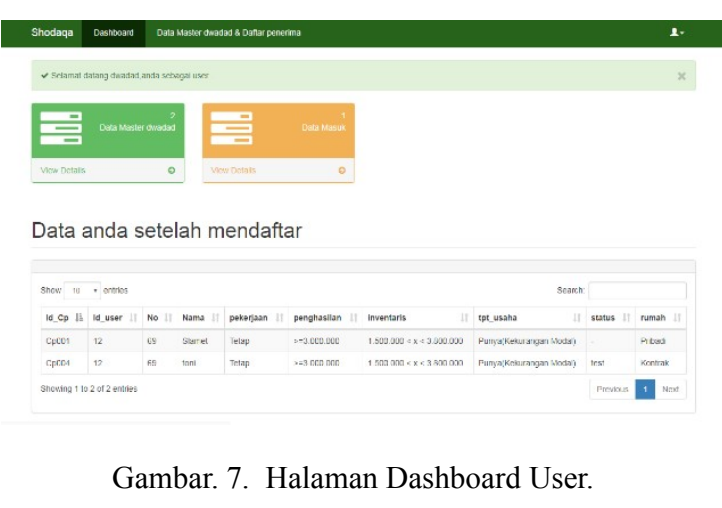

Halaman ini adalah halaman dashboard user yang menampilkan data setelah user melakukan pendaftaran penerima, dan informasi data yang masuk.

\section{Kesimpulan}

Simple Additive Weighting (SAW) dapat diterapkan untuk menentukan penetima shodaqo dengan kriteria tempat usaha, rumah, pekerjaan, inventaris yang dimiliki, dan penghasilan. Simple Additive Weighting (SAW) mempercepat proses penentuan penerima shodaqa berdasarkan data kriteria yang telah dipilih, sehingga memudahkan pihak panitia dalam menentukan penerima shodaqo. Simple Additive Weighting (SAW) ini memberikan informasi yang akurat setelah dilakukan proses analisa data dan aktivitas yang dilakukan begitu efisien.

\section{Daftar Pustaka}

Agustian, H., \& Jumaryadi, Y. (2019). Sistem Informasi Reservasi Kelas Kesehatan dan Pengelolaan Studio (Studi Kasus 
Studio Headspace Liza Natalia). JUST IT: Jurnal Sistem Informasi, Teknologi Informasi Dan Komputer, 10(1), 6-12.

Indrayani, H. (2012). Penerapan Teknologi Informasi dalam Peningkatan Efektivitas, Efisiensi dan Produktivitas Perusahaan. Jurnal EL-RIYASAH, 3(1), $48-56$.

Kurnianda, N. R. (2019). Multi-Attribute Decision Making Model for Acceptance of Prospective Corporate Employees with Interpolation Method. Journal of Physics: Conference Series, 1179, 012006. https://doi.org/10.1088/17426596/1179/1/012006

Mujiastuti, R., Komariyah, N., \& Hasbi, M. (2019). Sistem Penilaian Kinerja Karyawan Menggunakan Metode Simple Additive Weighting (SAW). Jurnal Sistem Informasi, Teknologi Informasi Dan Komputer, 9(2), 133141.

Nashar, M., Sukamto, A., \& Parashakti, R. D. (2016). Sistem Penunjang Keputusan (Decision Support System DSS) Untuk Pemilihan Karyawan Berprestasi Dengan Metode Simple Additive Weighting (Studi Kasus di Akademi Telekomunikasi Bogor). Jurnal Ilmiah Manajemen Dan Bisnis, 2(3), 882-891.

Priambodo, B., \& Jumaryadi, Y. (2018). Time Series Traffic Speed Prediction Using kNearest Neighbour Based on Similar Traffic Data. MATEC Web of Conferences, 218. https://doi.org/10.1051/matecconf/2018 21803021

Utami, E. R., Kresnawati, E., Saud, I. M., \& Rezki, S. B. (2017). Pengelolaan Potensi Zakat, Infak, Dan Shadaqah untuk Meningkatkan Kesejahteraan Masyarakat. Jurnal Berdikari, 5(22), 107-115. 